\title{
Retraction Note: Evaluation of agricultural climate and regional agricultural economic efficiency based on remote sensing analysis
}

\author{
Xiaolan Lu ${ }^{1}$
}

Published online: 22 November 2021

(c) Saudi Society for Geosciences 2021

Retraction Note: Arabian Journal of Geosciences (2021) 14: 858

https://doi.org/10.1007/s12517-021-07153-9

The Editor-in-Chief and the Publisher have retracted this article because the content of this article is nonsensical. The peer review process was not carried out in accordance with the Publisher's peer review policy. The author has not responded to correspondence regarding this retraction.

The original article can be found online at https://doi.org/10.1007/ s12517-021-07153-9.

\section{Xiaolan $\mathrm{Lu}$}

lux1123456@sina.com

1 School of Economics and Management, Hubei University of Arts and Science, Xiangyang, China 